\title{
Covid-19: Health needs of sex workers are being sidelined, warn agencies
}

\author{
Sally Howard
}

London, UK

Agencies have criticised the lack of action to protect the health needs of sex workers during the pandemic, with the English Collective of Prostitutes (ECP) warning of a "ticking time bomb of health problems."

Sex workers are at heightened risk of ill health, ${ }^{1}$ substance misuse, and violence, ${ }^{2}$ said the ECP, and unless the services they rely on resume normal operation soon and sex workers' financial hardship is tackled, their health problems will multiply. National Ugly Mugs, a sex worker safety scheme, told The BMJ that a survey of its members in late April found that they were struggling to access sexual health and family planning services, hygiene products, and antibiotics during the lockdown.

Healthcare for sex workers is provided by the NHS, charities, and faith based organisations, with services including drop-in clinics providing condom distribution, testing for sexually transmitted infections, and mental health support and outreach vans, which distribute food and condoms to street sex workers

NHS clinics across England and Wales have moved to phone consultations during the pandemic, ${ }^{3}$ minimising face-to-face appointments, a policy the ECP decried as "risky."

"Sex workers already face barriers to accessing healthcare, particularly marginalised groups like trans or migrant sex workers who are often not registered with a GP because of a fear of their data being passed to authorities," said a spokesperson.

Charity and faith based organisations are continuing to provide stripped back services, but with a focus on food and condom distribution to street workers. "We are continuing with our outreach vans five nights a week," said Amy Sutcliffe of Bristol faith based organisation One25. "But we've closed the clinic we run in partnership with out-of-hours primary care service BRISDoc. We don't know when things will get back to normal."

The ECP said that its members have complied with government advice around the pandemic and shuttered indoor settings such as saunas and brothels, increasing health risks for those who are forced to continue working on the streets because of financial hardship.
Raven Bowen, the head of National Ugly Mugs, similarly told The $B M J$ that it is concerned that some of its members are continuing to see clients in person, risking infection and physical violence and not seeking medical attention because of reduced healthcare provision.

Agencies and academics have also highlighted the negative effects of increased policing of sex workers' online activities during the pandemic.

Teela Sanders, a criminolgist who specialises in sex work, told The BMJ, "The role of police as public health enforcers is outside their comfort zone and can be clumsy. We know that police enforcement forces sex workers underground, leads to riskier behaviours, and reduces access to services such as healthcare."

The ECP fears a return to the treatment of sex workers during the HIV/AIDs epidemic, when women sex workers were scapegoated as vectors of disease. "We find it scandalous that police are surveilling sex workers for public health reasons," said the spokesperson, adding that the organisation is calling for an immediate moratorium on internet surveillance and property raids.

The Department for Health and Social Care told The BMJ that the government has provided the charity sector with $£ 750 \mathrm{~m}$ ( $€ 855 \mathrm{~m} ; \$ 922 \mathrm{~m}$ ) of funding to ensure the most vulnerable groups of society, including sex workers, are still able to access the vital services they need and that sexual and reproductive health services and GP surgeries remain open, although precautions are being taken to reduce face-to-face appointments.

1 Mastrocola EL, Taylor AK, Chew-Graham C. Access to healthcare for long-term conditions in women involved in street-based prostitution: a qualitative study. BMC Fam Pract 2015;16:118. 10.1186/s12875-015-0331-9 26338724

2 Deering KN, Amin A, Shoveller J, etal. A systematic review of the correlates of violence against sex workers. Am J Public Health 2014;104:e42-54.

10.2105/AJPH.2014.301909 24625169

3 Coronavirus update for sexual health and HIV services 2020. https://www.imperial.nhs. uk/our-services/sexual-health-and-hiv.

Published by the BMJ Publishing Group Limited. For permission to use (where not already granted under a licence) please go to http://group.bmj.com/group/rights-licensing/ permissions 